Brit. F. vener. Dis. (1970) 46, 469

\title{
Association of threads in the urine with non-gonococcal urethritis and prostatitis
}

\author{
J. J. MES SENT \\ St. Thomas' Hospital, London
}

In view of the appreciable number of cases of nongonococcal urethritis (NGU) which failed to clear up or relapsed after treatment with a 5-day course of oxytetracycline at St. Thomas' Hospital, observations were carried out in an effort to determine whether residual infection in the anterior or posterior urethra was primarily responsible for the persistence of threads in the first urine specimen of the two-glass test in the absence of obvious urethral discharge.

\section{Method and material}

When it had been established by the two-glass test that a patient had persistent urinary threads, the anterior urethra was irrigated with weak antiseptic solution to cleanse it before the two-glass test was performed again. Pelouse (1939) suggested that if the first glass was then clear, the threads previously present had come from Littré's glands of the anterior urethra. If threads were still present, however, they had come from the posterior urethra or prostate.

25 otherwise unselected patients with persistent threads in the urine after treatment for NGU with oxytetracycline $500 \mathrm{mg}$. four times a day for 5 days underwent anterior urethral irrigation.

\section{Results}

The first post-irrigation specimens of urine were clear in fourteen (56 per cent.), four showed specks (16 per cent.), and threads were seen in seven (28 per cent.). As Oates (1969) pointed out, many patients treated for NGU are left with asymptomatic prostatitis. Moist prostatic smears in the cases described above showed evidence of prostatitis (polymorphonuclear leucocytes with clumping) in three of the fourteen with clear urines after irrigation, in two of the four with specks, and in two of the seven showing threads. These figures indicate that 7 of 25 patients (28 per cent.) showing persistent threads in the urine had prostatitis after NGU had been treated with oxytetracycline. The results of urine examination after prelimininary anterior irrigation did not seem to be helpful as a diagnostic method, because a first clear urine did not exclude prostatitis, and threads did not establish its presence.

\section{Controls}

In a control series of fifteen cases of NGU, treated with the same dosage of oxytetracycline, in which the urine cleared with treatment, prostatitis was absent

Received for publication January 14, 1970 as judged by the examination of wet smears of expressed prostatic fluid.

\section{Results of culture examination}

Culture of specimens collected as described by Meares and Stamey (1968) was then carried out on a further 25 cases with persisting threads in the urine (see diagram). V.B.1 and V.B.2 were the first and second samples; E.P.S. was the prostatic bead, collected with precautions to exclude contamination, and V.B.3 was the final voided urine (see diagram after Meares and Stamey).

The results showed ' $T$ ' strain of mycoplasma present in four cases (16 per cent.), other organisms in twelve (48 per cent.), and Trichomonas vaginalis in two ( 8 per cent.). Thirteen of these 25 cases had prostatitis, but in five of these no organisms were demonstrated. Both cases of $T$. vaginalis infestation were associated with prostatitis. Only two cases of prostatitis were related to the presence of ' $T$ ' strain mycoplasma, and in one of them $T$. vaginalis coexisted.

\section{Summary}

Cases of non-gonococcal urethritis, with persistence of urinary threads after treatment with oxytetracycline, were examined to determine the site of origin of the threads and their relationship to prostatitis. The persistence of threads was frequently associated with prostatic involvement but this finding did not assist in elucidating the cause of the infection.

I should like to acknowledge the help and advice given by Dr. C. S. Nicol, Senior Consultant in Venereology to St. Thomas' Hospital, in the preparation of this paper.

\section{References}

Meares, E. M., and Stamey, T. A. (1968) Invest. Urol., 5,492

OAtes, J. K. (1969) Brit. F. Hosp. Med., 2, 556

Pelouze, P. S. (1939) "Gonorrhea in the Male and Female", 3rd ed., p. 109. Saunders. Philadelphia.

Relation entre les filaments urinaires de l'urétrite non gonococcique et la prostatite

Des malades atteints d'urétrite non-gonococcique, avec persistance de filaments urinaires après traitement par l'oxytétracycline, ont été examinés pour déterminer le siège d'origine des filaments et leur relation avec une Prostatite. La persistance de filaments coexista souvent avec une inflammation prostatique, mais ceci ne permit pas d'élucider la cause de l'infection. 